\title{
A VANET Routing Protocol based on the Road Vehicle Density Information in the City Environment
}

\author{
Yu Hyun ${ }^{+} \cdot$ Sanghyun Ahn ${ }^{++}$
}

\begin{abstract}
For the reliable delivery of safety-related information to vehicles in the VANET, a reliable VANET routing protocol is required. In this paper, we propose a routing protocol that works based on the road vehicle density information for fast and reliable communications among vehicles within the city environment VANET. In the proposed mechanism, each vehicle computes the road vehicle density by using beacon messages and the road information. Based on the road vehicle density information, each vehicle establishes a reliable route for packet delivery. Through the NS-2 based simulations, we compare our proposed mechanism with GPSR and show that our mechanism outperforms GPSR in terms of packet delivery success rate.
\end{abstract}

Keywords : VANET, Routing Protocol, Vehicle Density

\section{도시 환경에서 도로 차량 밀도 정보를 기반으로 하는 VANET 라우팅 프로토콜}

\author{
유 $\quad$ 현 $^{+}$. 안 상 현 ${ }^{++}$ \\ 요 약
}

\begin{abstract}
VANET에서는 차량 안전 관련 정보가 차량들 간에 안정적으로 전달될 수 있도록 해주는 라우팅 프로토콜이 요구된다. 본 논문에서는 도시 기반의 VANET 환경에서 차량 간의 빠르고 안정적인 통신을 위하여 차량 밀도 정보를 이용한 라우팅 기법을 제안한다. 제안 기법에서 각 차 량은 비콘 메시지와 도로 정보을 이용해서 도로의 차량 밀도를 계산한다. 차량들은 이 정보를 이용해서 패킷을 전송할 안정적인 경로를 설정한 다. NS-2 시뮬레이션을 통해 제안 기법과 GPSR의 성능을 비교했으며, 그 결과 제안 기법이 패킷 전송 성공률 측면에서 우수한 성능을 보임을 알 수 있었다.
\end{abstract}

키워드 : VANET, 라우팅 프로토콜, 차량 밀도

\section{1. 서 론}

VANET(Vehicular Ad Hoc Network)은 차량 간 무선 통 신이 가능한 네트워크로서, 차량 운전자에게 신속하고 신뢰 적으로 정보를 제공해줄 수 있는 신뢰적인 라우팅 프로토콜 을 필요로 한다[1]. MANET 라우팅 프로토콜을 VANET에 서 사용할 수도 있지만 MANET과 달리 VANET은 전력과 단말 크기에 제약이 없으며 쉽게 GPS(Global Positioning

※ 본 연구는 지식경제부 및 정보통신산업진흥원의 대학 IT연구센터 지원 사업의 연구결과로 수행되었음(NIPA-2012-H0301-12-4004)

※ 이 논문은 2010 년도 정부(교육과학기술부)의 재원으로 한국연구재단의 지원을 받아 수행된 연구임(No. 2010-0027410).

† 준 회 원 : 시큐아이닷컴 R\&D 센터 선임연구원

†† 종신회원 : 서울시립대학교 컴퓨터과학부 교수

논문접수 : 2013년 1월 22일

심사완료 : 2013년 3월 11일

* Corresponding Author: Sanghyun Ahn(ahn@uos.ac.kr)
System)를 이용할 수 있어서, 위치 기반 라우팅 프로토콜 (geographical routing protocol)[2]을 사용하기가 용이하다.

대표적인 위치 정보 기반 라우팅 프로토콜로는 GPSR (Greedy Perimeter Stateless Routing)[3]이 있다. GPSR은 그리디 기법을 이용해서 이웃 노드들 중에서 목적지 노드에 가장 근접한 노드로 패킷을 전달하는 방식을 사용하며, 소 스 노드에서 목적지 노드까지 전체 경로를 설정하지 않고 목적지 노드의 위치와 이웃 노드의 위치만을 이용해서 데이 터 패킷을 다음-홉(next-hop) 노드로 전달한다. 그러나 차 량의 고속 이동성, 교통의 흐름에 따른 차량 밀도의 변화, 운전자의 운행 습관 등에 따라 망 토폴로지(topology)가 급 격하게 변하는 특징을 갖는 VANET 환경에서 GPSR은 매 우 낮은 성능을 보인다. 특히 차량 밀도가 가변적인 도시 환경에서 GPSR을 사용하게 되면, 거리상으로는 가깝지만 패킷을 전달해주는 매개체인 차량의 밀도가 낮아서 경로 손 
실이 생길 가능성이 높은 경로로 패킷을 전달하는 문제가 생길 수 있다.

따라서 본 논문에서는 도시 기반의 VANET 환경에서 차 량 간에 보다 안정적인 통신을 할 수 있도록 도로의 차량 밀도 정보를 이용한 라우팅 기법을 제안한다. 본 논문의 구 성은 다음과 같다. 2장에서는 관련 연구를 소개하며, 3장에 서는 제안하는 라우팅 기법에 대해 설명하고, 4장에서 NS-2 시뮬레이션을 통해 제안 기법과 GPSR의 성능을 비교 분석 한다. 마지막으로 5 장에서 결론을 맺는다.

\section{2. 관련 연구}

기존의 VANET 라우팅 프로토콜에 대한 대부분의 연구는 위치 정보 기반 라우팅 프로토콜을 확장하는 데 초점을 두고 있다 (예, CAR[4], A-STAR[5], VADD[6] 등) [2]. GPSR[3] 은 대표적인 위치 정보 기반 라우팅 프로토콜로서 그리디 포 워딩(greedy forwarding)을 사용한다. GPSR에서는 주기적으 로 비콘(beacon) 메시지를 주변 이웃 노드들에게 1-홉 브로 드캐스트(one-hop broadcast)하고 이를 통해 주변 이웃 노드 들의 위치 정보를 수집한다. 그리고 이 위치 정보를 기반으 로 목적지 노드와의 거리를 계산하여 목적지 노드와 가장 가 까운 이웃 노드에게 패킷을 전달하는 그리디 포워딩을 사용 한다. 그러나 그리디 포워딩은 이웃 노드들의 위치를 정확하 게 수집해야 하고 다양한 방향에 이웃 노드들이 위치하고 있 어야 하기 때문에 이 방식은 소스 노드와 목적지 노드 사이 에 충분한 중간 노드들과 이동성이 적은 환경에서 좋은 성능 을 보인다. 따라서 GPSR은 도시 기반의 VANET 환경과 같 이 도로의 배치와 차량 밀도에 따라 토폴로지의 변화가 급격 한 환경에는 적합하지 않다. 예를 들어, Fig. 1과 같은 환경 에서 그리디 포워딩을 사용하면 가장 짧게 목적지 노드로 패 킷을 보내기 위해 점선 화살표와 같은 경로를 선택하게 되 며, 이 경우 도로의 차량 밀도가 낮아 패킷을 전달할 수 없 는 상황이 쉽게 발생하고 이를 복구하기 위해 perimeter mode로 동작하게 된다. 그러나 도로의 차량 밀도가 낮기 때 문에 perimeter mode도 제대로 동작하지 않아서 비효율적인 상황이 자주 발생하게 된다. 기존에 제안된 VANET 라우팅 프로토콜들은 GPSR을 기반으로 제안되고 차량 밀도에 대한 부분은 고려하지 않았기 때문에 차량 밀도에 따라 성능이 매 우 낮아질 수 있다. 따라서 본 논문에서는 도로의 차량 밀도 정보를 이용해서 안정적인 경로를 설정할 수 있는 라우팅 기 법을 제안하며, 이웃 노드의 위치 정보뿐만 아니라 도로의 차량 밀도 정보도 사용함으로써 Fig. 1에서 실선 화살표와 같이 차량 밀도가 충분히 높은 경로를 통해 패킷을 신뢰적으 로 목적지 노드로 전달할 수 있게 한다.

\section{3. 차량 밀도를 이용한 라우팅 기법}

본 논문에서는 소스 노드가 높은 차량 밀도를 갖고 있는 도로를 선택해서 목적지 노드까지의 경로를 설정해주는 라

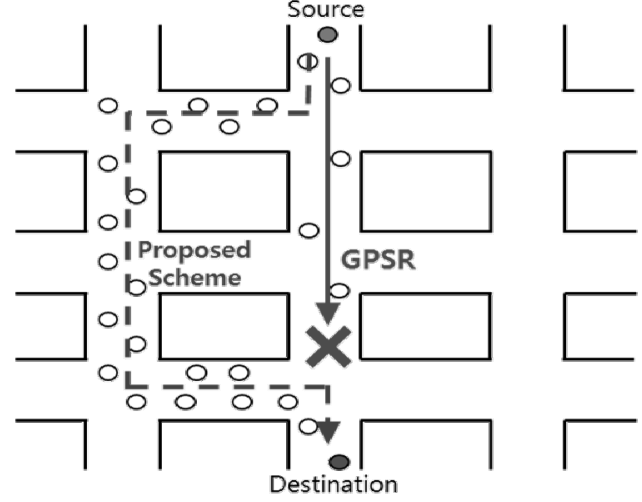

Fig. 1. Routes determined by GPSR and the proposed scheme

우팅 기법을 제안한다. 모든 노드들이 GPS를 장착하고 있 고 디지털 지도 정보를 갖고 있어서 도로들의 위치 정보를 알 수 있는 환경을 가정한다.

도로의 차량 밀도를 측정하기 위해 모든 차량이 이웃 차 량들에게 주기적으로 비콘 메시지를 1-홉 브로드캐스팅하고 이를 이용해 만들어지는 도로 정보를 이용한다. 비콘 메시 지는 GPSR의 비콘 메시지와 비슷하지만 위치정보 이외에 이동 방향, 도로의 역방향 차량 수(Total number of Reverse Cars; TRC) 정보를 추가적으로 갖고 있다.

각 차량은 자신이 속한 도로의 차량 밀도를 측정하고 유 지하기 위해 비콘 메시지를 통해 도로 정보(Road Information; RI)를 구성하며, RI는 차량이 도로에 진입하거 나 역방향 차량으로부터 비콘 메시지를 수신하면 갱신된다. $\mathrm{RI}$ 는 도로 이름, 도로 진입 시각, 도로 차량 밀도, 역방향 차량 수 값을 갖는 Road, Entrance Time, Density of Cars, Reverse Cars 필드들로 구성된다.

각 차량은 도로의 차량 밀도 정보를 측정하기 위해 이웃 차량으로부터 비콘 메시지를 수신하면 비콘 메시지의 TRC 값과 $\mathrm{RI}$ 의 Reverse Cars 값을 이용해서 자신의 $\mathrm{TRC}$ 를 계 산하고 이 값을 비콘 메시지에 포함시켜 보낸다.

$$
T R C=M_{c} \times \frac{R_{d}}{C_{d}}
$$

식 (1)에서 $M_{c}$ 는 마주친 역방향의 차량 수(RI의 Reverse Cars 필드 값), $C_{d}$ 는 도로에 진입해서 이동한 거리, $R_{d}$ 는 도 로의 전체 길이를 의미한다.

비콘 메시지를 수신했을 때, 비콘 메시지를 보낸 노드의 이동 방향이 자신과 역방향이면 RI의 Reverse Cars 필드 값 을 1 증가시킨다. 그리고 다음과 같이 도로의 차량 밀도를 계산해서 RI의 Density of Cars $(\mathrm{DC})$ 필드 값을 수정한다.

$$
\begin{aligned}
& D C_{n}=R_{\text {TRC }}+S_{\text {TRC }} \\
& \overline{\mathrm{DC}}_{\mathrm{n}}=\alpha \cdot C_{n}+(1-\alpha) \cdot \overline{D C}_{n-1}
\end{aligned}
$$


식 (2)에서 $R_{T R C}$ 는 비콘 메시지를 수신한 노드의 $\mathrm{TRC}$ 값을 의미하고 $S_{T R C}$ 는 비콘 메시지 안에 포함되어 있는 $\mathrm{TRC}$ 값을 의미한다. 식 (3)에서 $\bar{C}_{n-1}$ 은 이전 비콘 메 시지를 받았을 때 계산되었던 차량 밀도 값이고 $\alpha$ 는 평균 을 구하기 위한 가중치이다.

경로를 탐색하기 위해 DSR[7]과 유사하게 RREQ(Route Request) 메시지와 RREP(Route Reply) 메시지를 사용하며, 차량 밀도 및 거쳐간 도로 정보는 $\mathrm{RREQ}$ 메시지의 RoadList, RoadHop, MinDensity 필드에 포함된다. RoadList, RoadHop, MinDensity 필드는 각각 거쳐가는 도 로 목록, 거쳐가는 도로 수, 도로 차량 밀도들 중 최소 값을 포함한다.

소스 노드는 경로 설정을 위해 $\mathrm{RREQ}$ 메시지에 자신이 속한 도로 정보를 RoadList 필드에 포함시킨 후 브로드캐스 팅 한다. RREQ 메시지는 목적지 노드까지 브로드캐스팅 되 면서 거쳐온 도로 정보들을 RoadList 필드에 갖게 된다. 중 간 노드가 $\mathrm{RREQ}$ 메시지를 수신하면 다음과 같이 동작한다.

1) RREQ 메시지의 소스 노드 주소가 라우팅 테이블에 없고 자신이 속해 있는 도로 정보가 RoadList 필드에 없으 면 라우팅 테이블에 소스 노드 주소, RoadList 필드에 있는 도로 정보들, RoadHop 필드 값과 MinDensity 필드 값을 추 가한다. 그리고 RoadList 필드에 자신의 도로 정보를 추가 한 후 RI의 $\mathrm{DC}$ 필드 값이 MinDensity 필드 값보다 작으면 MinDensity 필드 값을 $\mathrm{DC}$ 필드 값으로 교체하고 RREQ 메 시지를 포워딩한다.

2) RREQ 메시지의 소스 노드 주소가 라우팅 테이블에 있고 RoadList 필드 값과 자신의 라우팅 테이블이 일치하지 않으면, 거쳐온 도로의 수를 비교한다. RoadHop 필드의 값 이 기존 라우팅 테이블의 RoadHop 필드 값보다 $\mathrm{k}(\mathrm{k}>0)$ 이상 크면 RREQ 메시지를 폐기하고 그렇지 않으면 차량 밀도를 비교한다. 기존 라우팅 테이블의 MinDensity 필드 값이 $\mathrm{RREQ}$ 메시지의 MinDensity 필드 값보다 크면, $\mathrm{RREQ}$ 메시지를 폐기하고 그렇지 않으면 포워딩 한다.

3) 목적지 노드는 처음 RREQ 메시지를 받으면 바로 $\mathrm{RREP}$ 메시지를 보내지 않고 일정 시간 동안 다른 경로를 통해서 오는 RREQ 메시지를 기다린 후에 MinDensity 필드 값이 가장 큰 경로를 선택하여 RREP 메시지를 소스 노드로 보낸다.

4) 소스 노드가 RREP 메시지를 수신하면 RREP 메시지 안에 들어 있는 도로 정보들을 이용하여 소스 라우팅을 통 해 데이터 패킷을 목적지 노드로 보낸다.

\section{4. 성능 평가}

제안한 라우팅 기법의 성능을 평가하기 위해 NS-2[8] 시 뮬레이터를 이용했다. 성능 비교 대상으로 GPSR을 선택했 으며, MAC 프로토콜은 IEEE 802.11, 데이터 전송률은

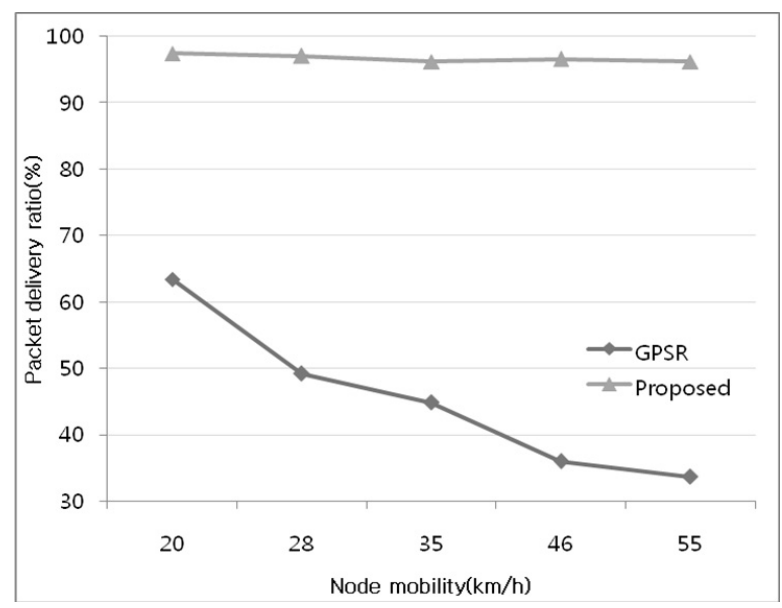

Fig. 2. Packet delivery ratio vs. node mobility

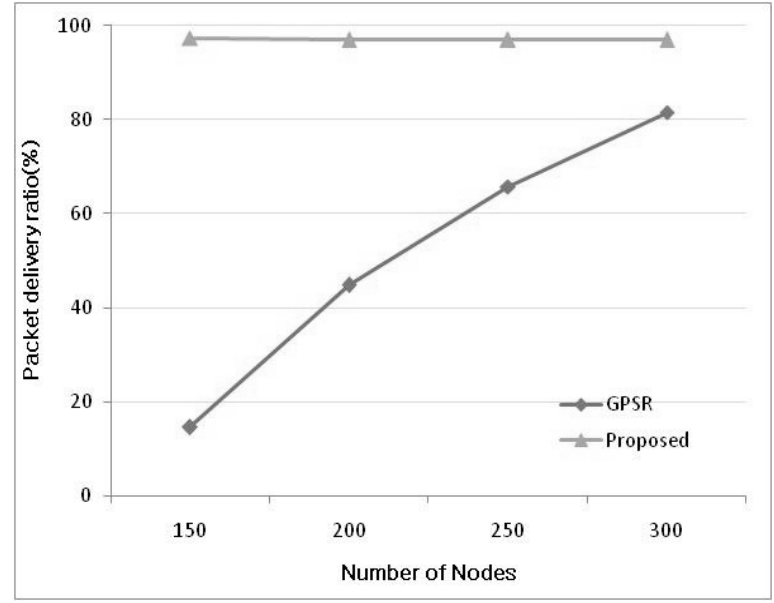

Fig. 3. Packet delivery ratio vs. the number of nodes

$2 \mathrm{Mbps}$ 로 설정했다. 시뮬레이션 망은 $3000 \mathrm{~m}$ x $3000 \mathrm{~m}$ 안 에 도로를 배치하고 양방향으로 차량이 이동하게 했다. 노 드의 전송 범위는 $250 \mathrm{~m}$, 간섭 범위는 $500 \mathrm{~m}$ 로 설정했다. 도로의 간격은 $300 \mathrm{~m}$, 차량의 수는 150 대에서 300 대, 차량 의 이동 속도는 $20 \mathrm{~km} / \mathrm{h}$ 에서 $55 \mathrm{~km} / \mathrm{h}$ 로 증가시키면서 실험 했다. 또한 각 도로에 이동하는 차량의 수는 각 도로마다 다른 분포를 갖도록 배치했다. 즉, 시뮬레이션 망에 평균적 으로 많은 차량이 지나다니는 도로와 그렇지 않은 도로를 랜덤하게 배치했다.

Fig. 2는 차량의 수를 200대, CBR rate를 $20 \mathrm{kbps}$ 로 설정 하고 차량의 이동 속도를 $20 \mathrm{~km} / \mathrm{h}$ 에서 $55 \mathrm{~km} / \mathrm{h}$ 로 증가시키 면서 패킷 전송률을 측정한 결과이다. 차량의 수가 고정된 상황에서 차량의 이동 속도가 증가하게 되면 차량들 간의 속도 차이로 인해 차량의 밀도가 낮아지는 도로가 빈번하게 발생한다. GPSR은 이런 변화를 인지하지 못하고 차량 밀도 가 낮은 도로로 패킷을 많이 전달하여 전송이 실패할 확률 이 높아지기 때문에 차량의 이동속도가 증가함에 따라 패킷 전송률이 낮아진다. 그러나 제안 기법은 실시간으로 측정된 차량 밀도 정보를 이용하여 보다 안정적인 경로로 패킷을 
보내기 때문에 차량의 이동속도에 크게 영향을 받지 않고 GPSR 기법에 비해 패킷 전송률이 높다.

Fig. 3은 차량의 평균 이동 속도를 $35 \mathrm{~km} / \mathrm{h}, \mathrm{CBR}$ rate를 $20 \mathrm{kbps}$ 로 설정하고 차량의 수를 150 대에서 300 대로 증가시 키면서 패킷 전송률을 측정한 결과이다. 차량의 수가 증가 하게 되면 패킷을 전달해주는 매개체인 차량의 밀도가 증가 하므로 GPSR의 패킷 전송률은 증가하게 된다. 그러나 그림 에서 볼 수 있듯이 차량의 밀도가 낮을 때는 GPSR은 매우 안 좋은 패킷 전송률을 보인다. 제안한 라우팅 기법은 차량 의 밀도가 높은 도로를 통해 패킷을 전달해주므로 항상 패 킷 전송률이 높음을 확인할 수 있다.

\section{5. 결 론}

VANET은 불규칙한 토폴로지 변화 등으로 인해 다른 무 선 통신망보다 잦은 네트워크 단절, 짧은 링크 연결 시간, 높은 패킷 손실률 등의 단점을 가진다. 본 논문에서는 도로 의 차량 밀도를 측정하고 보다 높은 차량 밀도를 가진 도로 를 통하여 차량 간 안정적인 통신을 할 수 있도록 경로 설 정을 해주는 라우팅 기법을 제안했다. 제안한 라우팅 기법 의 성능을 분석하기 위해 NS-2 기반의 시뮬레이션을 수행 했으며, 그 결과 기존의 그리디 포워딩을 사용하는 GPSR에 비해 제안 방식이 안정적인 경로 설정을 통해 패킷 전송률 측면에서 매우 우수한 성능을 보임을 알 수 있었다. 앞으로 제안 기법이 차량 수의 변화 및 토폴로지 변화에 따라 발생 하는 장단점에 대한 분석을 할 예정이다.

\section{참 고 문 헌}

[1] F. Li and Y. Wang, "Routing in Vehicular Ad Hoc Networks: A Survey”, IEEE Vehicular Technology Magazine, 2007.

[2] S.-H. Cha, M.-W. Ryu, and K.-H. Cho, "A Survey of Greedy Routing Protocols for Vehicular Ad Hoc Networks," Smart Computing Review, 2012.

[3] B. Karp and H. T. Kung, "GPSR: Greedy Perimeter Stateless Routing for Wireless Networks," ACM /IEEE International Conference on Mobile Computing and Networking (MobiCom), 2000.
[4] V. Naumov and T. Gross, "Connectivity-Aware Routing (CAR) in Vehicular Ad Hoc Networks," IEEE International Conference on Computer Communications, 2007.

[5] C. Lochert, M. Mauve, H. F?ßler, and H. Hartenstein, "Geographic Routing in City Scenarios," ACM SIGMOBILE Mobile Computing and Communications Review (MC2R), 2005.

[6] J. Zhao and G. Cao, "VADD: Vehicle-Assisted Data Delivery in Vehicular Ad Hoc Networks," IEEE International Conference on Computer Communications, 2006.

[7] D. B. Johnson, D. A. Maltz, and Y.-C. Hu, "The Dynamic Source Routing Protocol for Mobile Ad Hoc Networks(DSR)", IETF RFC 4728, 2007.

[8] The Network Simulator, NS-2, http://www.isi.edu/nsnam/ns.

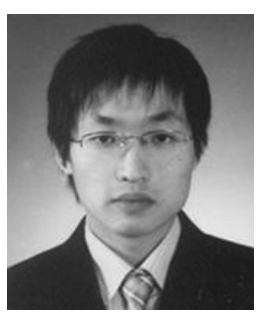

유 현 e-mail : finalyu@gmail.com 2005년 백석대학교 컴퓨터과학부(학사) 2007년 서울시립대 컴퓨터통계학과(석사) 2012년 현 재 시큐아이닷컴 R\&D 센터 선임연구원 관심분야: MANET, VANET

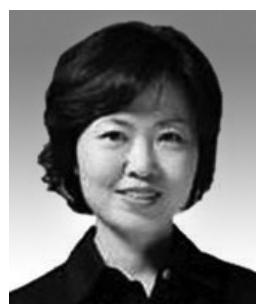

\section{안 상 현}

e-mail :ahn@uos.ac.kr 1986년 서울대학교 컴퓨터공학과(학사) 1988년 서울대학교 컴퓨터공학과(석사) 1993년 미네소타대학교 컴퓨터과학과 (박사) 1988년 1989년 (주)데이콤 연구원 1994년 1998년 세종대학교 컴퓨터학과 교수 1998년 현 재 서울시립대학교 컴퓨터과학부 교수 관심분야: Wireless Sensor Network, MANET, VANET, 인터넷, 라우팅 프로토콜, 유무선통신망 